\title{
Quantitative cardiac MR assessment of left ventricular diastology
}

\author{
Kyle Lehenbauer ${ }^{1}$, Kevin Kalisz', Benjamin H Freed ${ }^{2}$, Xiaoming Bi ${ }^{3}$, Christoph Guetter ${ }^{4}$, Marie-Pierre Jolly ${ }^{4}$, \\ Marius Cordts ${ }^{4}$, Lewis C Sommerville ${ }^{1}$, Keyur Parekh ${ }^{1}$, Michael Markl ${ }^{1}$, James Carr ${ }^{1}$, Jeremy Collins ${ }^{{ }^{*}}$ \\ From 16th Annual SCMR Scientific Sessions \\ San Francisco, CA, USA. 31 January - 3 February 2013
}

\section{Background}

Cardiac MR (CMR) is the accepted gold standard for the assessment of myocardial scar and biventricular systolic function. Bright blood cine imaging with phase-contrast mitral inflow assessment has shown promise for the evaluation of left ventricular (LV) diastology. The purpose of this study is to evaluate the accuracy of LV diastolic function grading by CMR, using Doppler echocardiography as the reference standard. We hypothesize that quantitative CMR analysis of diastolic function coupled with left atrial volume (LAV) assessment is accurate in characterizing LV diastology.

\section{Methods}

83 patients without mitral valve disease (47 men, average age 53 years) underwent CMR imaging on a $1.5 \mathrm{~T}$ scanner for evaluation of myocardial viability or infiltrative heart disease. All patients underwent 2-D phase-contrast (PC) imaging of the mitral valve (TR/TE 48/2.2, FA 30 degrees, VENC $80 \mathrm{~cm} / \mathrm{s}, 20$ phases, bw 554). Brightblood (BB) 4- and 2-chamber cine imaging was performed (TR/TE 13/1.1, FA 69 degrees, 40 to 50 phases, BW 933) for lateral mitral annular and left atrial volume (LAV) assessment. Peak E and A velocities were obtained from PC data. 4-chamber BB cine images were analyzed using prototype software evaluating deformation fields to automatically identify and track the mitral base plane at the lateral and septal insertions, extracting lateral e' values (Siemens Corp., Corporate Technology, Princeton, New Jersey). LAV was obtained using the lengtharea method. LV diastolic function was graded using established echocardiographic criteria. Differences in means were assessed using the student's t-test.

\section{Results}

Echocardiographic LV diastolic function was indeterminate in 30 patients $(36 \%)$. CMR correctly categorized $95 \%, 80 \%, 50 \%$, and $50 \%$ of patients with normal, grade I, grade II, or grade III LV diastolic dysfunction by echocardiography with an overall accuracy of $77 \%$ (Table 1). CMR underestimated echocardiographically determined lateral annular e' and mitral inflow E velocities by $36 \%$ and $54 \%$ respectively. CMR and echocardiographically determined E:A ratios were not significantly different by diastolic dysfunction grade ( $p>0.05)$. E:e' ratios were similar for grade I and III LV diastolic dysfunction ( $p>0.05)$, but were statistically different for grade II dysfunction $(\mathrm{p}=0.03)$, with a trend towards higher CMR determined E:e' values (average 16.8 vs 10.5 respectively).

\section{Conclusions}

Quantitative CMR assessment of LV diastolic function is clinically feasible and accurate when using the LAVi to distinguish normal and pseudonormal patterns. Additional work is ongoing to improve CMR grading of LV diastolic dysfunction in the context of an elevated LAVi.

\section{Funding}

Dr. Collins is supported by the RSNA R\&E Foundation and the SIR Foundation. Dr. Markl is supported by the $\mathrm{NIH}$ on a R01 as well as NUCATS.

'Radiology, Northwestern University, Chicago, IL, USA

Full list of author information is available at the end of the article 


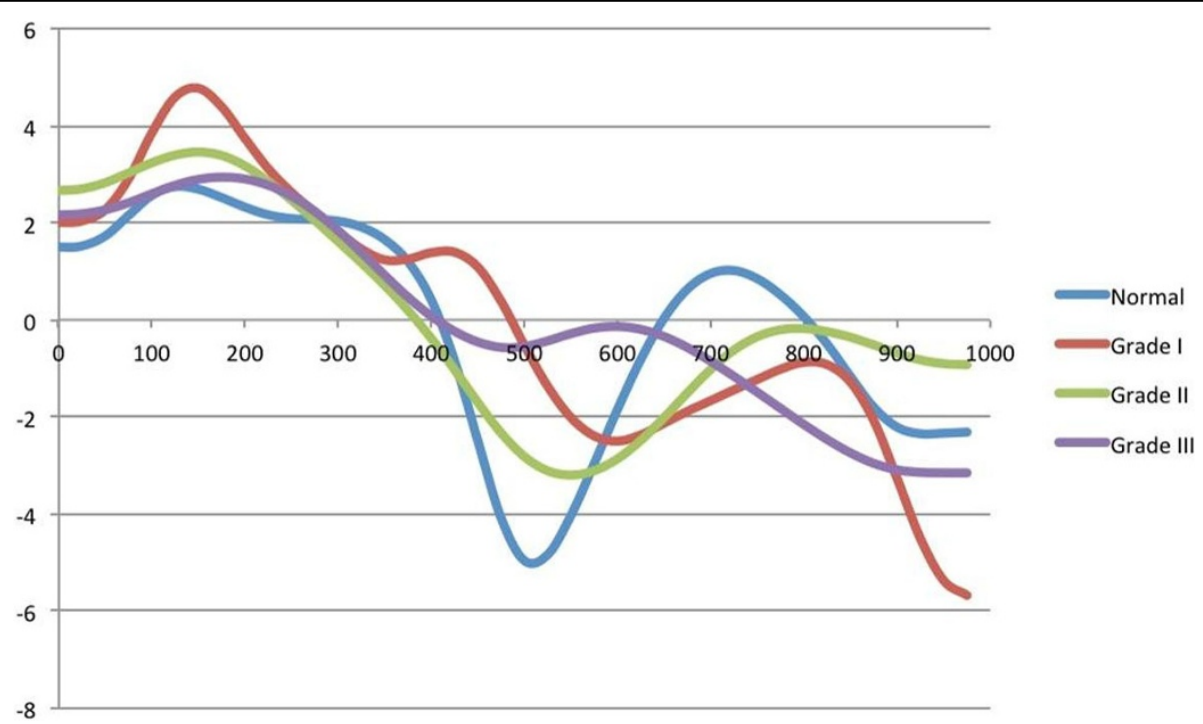

Figure 1 CMR lateral annular $e^{\prime}$ velocities in four subjects demonstrating waveforms in patients with normal diastolic function as well as patients with grade I, grade II and grade III diastolic function. Individual patient's heart rates were extrapolated to 60 bpm for illustration purposes.

Table 1 LV diastolic function CMR classification by echocardiographic diastolic assessment

\begin{tabular}{ccccccc}
\hline \multicolumn{7}{c}{ CMR classification } \\
\hline $\begin{array}{c}\text { Echo } \\
\text { classification }\end{array}$ & Total & Normal & $\begin{array}{c}\text { Grade } \\
\text { I }\end{array}$ & $\begin{array}{c}\text { Grade } \\
\text { II }\end{array}$ & $\begin{array}{c}\text { Grade } \\
\text { III }\end{array}$ & $\begin{array}{c}\text { Correctly } \\
\text { classified }\end{array}$ \\
\hline Normal & 22 & 21 & 0 & 1 & 0 & $95 \%$ \\
Grade I & 15 & 0 & 12 & 3 & 0 & $80 \%$ \\
Grade II & 12 & 0 & 4 & 6 & 2 & $50 \%$ \\
Grade III & 4 & 0 & 1 & 1 & 2 & $50 \%$ \\
\hline
\end{tabular}

\section{Author details}

${ }^{1}$ Radiology, Northwestern University, Chicago, IL, USA. ${ }^{2}$ Cardiology, Northwestern University, Chicago, IL, USA. ${ }^{3}$ Cardiovascular MR R\&D, Siemens Healthcare, Chicago, IL, USA. ${ }^{4}$ Siemens Corp., Corporate Technology, Princeton, NJ, USA.

Published: 30 January 2013

\section{Submit your next manuscript to BioMed Central} and take full advantage of:

- Convenient online submission

- Thorough peer review

- No space constraints or color figure charges

- Immediate publication on acceptance

- Inclusion in PubMed, CAS, Scopus and Google Scholar

- Research which is freely available for redistribution

Submit your manuscript at www.biomedcentral.com/submit 